\title{
Physiotherapy combined with therapeutic neuroscience education versus physiotherapy alone for patients with chronic low back pain: A pilot, randomized-controlled trial
}

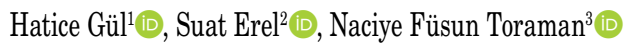 \\ ${ }^{1}$ Program of Physiotherapy, Akdeniz University, Vocational School of Health Services, Antalya, Turkey \\ ${ }^{2}$ Pamukkale University, School of Physical Therapy and Rehabilitation, Denizli, Turkey \\ ${ }^{3}$ Department of Physical Medicine and Rehabilitation, Univesity of Health Sciences, Antalya Training and Research Hospital, Antalya, Turkey
}

Received: November 11, 2019 Accepted: June 25, 2020 Published online: September 01, 2021

\begin{abstract}
Objectives: The aim of this study was to investigate the effect of therapeutic neuroscience education (TNE) combined with physiotherapy on pain, kinesiophobia, endurance, and disability in chronic low back pain (CLBP) patients.

Patients and methods: Between November 2016 and December 2017, a total of 31 patients with CLBP (5 males, 26 females; mean age: $42.3 \pm 10.8$ years; range, 20 to 58 years) were randomly allocated to receive physiotherapy combined with TNE (experimental group, EG, $\mathrm{n}=16$ ) and physiotherapy alone (control group, CG, $\mathrm{n}=15$ ). All participants received physiotherapy consisting of five sessions per week for a total of three weeks. In addition to physiotherapy, the EG received TNE sessions consisting of two sessions per week for a total of three weeks. The primary outcomes were pain intensity as assessed by Visual Analog Scale (VAS) and kinesiophobia by Tampa Scale for Kinesiophobia (TSK), while and the secondary outcomes were trunk muscle endurance as assessed by the partial curl-up test (trunk flexor endurance [TFE]) and modified Sorensen test (trunk extensor endurance [TEE]) and disability by Roland-Morris Disability Questionnaire (RMDQ).
\end{abstract}

Results: All patients completed the study. The median VAS, TSK, TFE, TEE, and RMDQ scores for the EG significantly improved after three weeks, while there was only significant improvement in the VAS, TSK, and RMDQ scores in the CG. The TSK decreased more in the EG than in the CG. The significant difference was evident in TSK and TFE in favor of the EG $(\mathrm{p}<0.05)$.

Conclusion: These results suggest that the combination of TNE with physiotherapy can improve kinesiophobia and trunk flexor muscle endurance of patients with CLBP in the short-term.

Keywords: Education; kinesiophobia; low back pain; modalities; pain; physical therapy.

Pain is often seen as a symptom signaling the underlying primary pathology. However, chronic pain is defined as pain that persists beyond the normal tissue-healing process without a significant biological component and lasting more than three months. ${ }^{[1]}$ In a systematic review of the literature, psychosocial factors such as fear of movement and catastrophizing are among the factors which cause acute low back pain to progress to chronic low back pain (CLBP). ${ }^{[2]}$ Ongoing fear and catastrophizing in patients with CLBP lead to increased pain, disability and kinesiophobia, and decreased endurance of trunk muscles. ${ }^{[3]}$ Currently, recurrent low back pain complaints have been increasing day by day. Therefore, treatment strategies aiming at reducing the negative effects of psychosocial factors in patients with CLBP are important for healing.

Corresponding author: Hatice Gül. Akdeniz Üniversitesi Sağlık Hizmetleri Meslek Yüksekokulu, Fizyoterapi ve Rehabilitasyon Bölümü, 07058 Konyaaltı, Antalya, Türkiye. e-mail: fzt-hatice@hotmail.com 
In the literature, the use of passive treatment strategies such as electrophysical agents and manual therapy alone has been shown to limit the effects on CLBP treatment in the long-term and active physiotherapy methods including exercise are recommended for individuals with CLBP. ${ }^{[4,5]}$ The effect of exercise on pain and disability in individuals with CLBP has been addressed in the literature. It is usually thought that exercise reduces pain and disability via improvement in physical performance (i.e., range of motion, muscle strength, and endurance). However, for CLBP conditions, decreased pain and disability during an exercise program did not correlate with changes in physical performance. ${ }^{[6]}$ In previous studies, decreasing pain and disability were associated with improved psychosocial status, cognition (decreasing fear-avoidance behavior and anxiety), and functional and structural adaptation in the brain, rather than physical performance. ${ }^{[7-9]}$ Exercise programs and physiotherapies created by ignoring psychosocial factors such as maladaptive beliefs, fear and catastrophizing may adversely affect the patient's struggle with CLBP. Therefore, the use of patient education programs, which are advocated to reduce fear-avoidance behavior, catastrophic thought, and kinesiophobia has become prominent in the treatment of CLBP.

Education is a method used by physiotherapists for many years to help reducing disability due to low back pain. ${ }^{[10-13]}$ Therapeutic neuroscience education (TNE) is an educational model which increases the patient's level of knowledge about pain neurophysiology. The mechanism of TNE is based on the knowledge about pain. After TNE sessions, patients are able to reconceptualize their pain and become aware of that pain is not equal to harm, persisting pain is not correlated with tissue damage, pain is modulated by many factors, and pain occurs based on perception of danger. ${ }^{[14]}$ Theoretically, increasing knowledge about pain may reduce pain, which is related to fear, and disability and improve physical and mental health. ${ }^{[15,16]}$ The TNE consists of educational sessions in which the physiology of the nervous system, as well as the neurobiology of pain are explained to the patient in an easy-tounderstand manner through the use of drawings, prepared pictures, examples, metaphors and leaflets to supplement explanations. In a systematic review investigating the effect of TNE on CLBP, the combination of TNE with active and passive treatment methods was found to significantly affect the success of the treatment. ${ }^{[17]}$
Although there are studies regarding the combination of TNE with exercise in CLBP, no study is available which combine electrophysical agents, exercise, and TNE methods in the literature. In the present study, therefore, we aimed to investigate whether TNE combined with physiotherapy consisting of electrophysical modalities and home-based exercise was superior to physiotherapy program alone in patients with CLBP.

\section{PATIENTS AND METHODS}

\section{Study design and study population}

This pilot, two-arm, parallel-group, randomizedcontrolled study was conducted at Antalya Training and Research Hospital, Physical Medicine and Rehabilitation outpatient clinic between November 2016 and December 2017. Prior to the study, a written informed consent was obtained from each participant. The study protocol was approved by the Pamukkale University Medical Ethics Committee (date, no: 10/02/2016, 60116787-020/8825). The study was conducted in accordance with the principles of the Declaration of Helsinki.

Patients admitted to our outpatient clinic who met the inclusion and exclusion criteria were selected for the study. Inclusion criteria were as follows: age between 18 and 60 years, having CLBP for longer than three months, having independent walking ability, and to be literate in Turkish. Those having vertebral compression fractures, transitional vertebrae, an underlying tumoral, rheumatologic or inflammatory disease, acute trauma, surgical history, and pregnant women or having delivery within the past six months were excluded from the study.

\section{Randomization}

A total of 31 patients with CLBP (5 males, 26 females; mean age: $42.3 \pm 10.8$ years; range, 20 to 58 years) were randomly allocated to receive physiotherapy combined with TNE (experimental group, $\mathrm{EG}, \mathrm{n}=16$ ) and physiotherapy alone (control group, CG, $\mathrm{n}=15$ ). Randomization was based on using the Microsoft Office Excel (Microsoft Corp., WA, USA) randomization equation with stratification according to age and Visual Analog Scale (VAS) components. The study flow chart was developed in accordance with the CONSORT guideline and is shown in Figure 1.

\section{Interventions}

All participants underwent a three-week treatment program consisting of 15 sessions of physiotherapy 


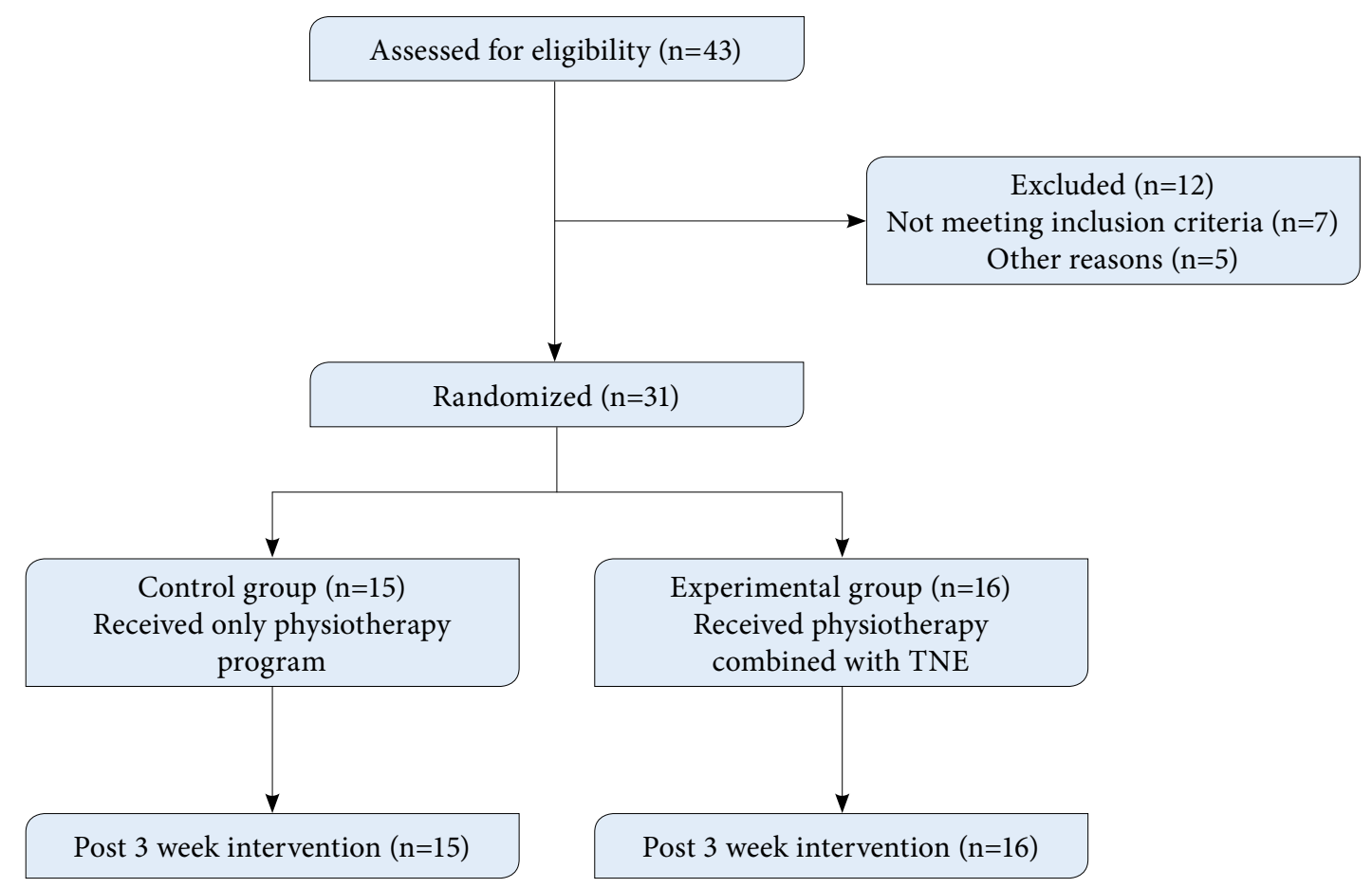

Figure 1. Study flow chart.

program. The EG received two sessions of TNE per week in addition to physiotherapy sessions.

Hot-pack, ultrasound, and transcutaneous nerve electrical stimulation (TENS) were applied to the individuals within the physiotherapy program and home-based exercise program given to the individuals by a physiotherapist. Hot-pack was applied for $20 \mathrm{~min}$. The TENS was applied at the beginning of the treatment as the conventional TENS $(80 \mu \mathrm{sec} / 100 \mathrm{~Hz})$, and, in subsequent sessions, as the acupuncture TENS $(200 \mu \mathrm{sec} / 5 \mathrm{~Hz})$ for $20 \mathrm{~min}$. Ultrasound was performed for $10 \mathrm{~min}$ at a $1.5 \mathrm{Watt} / \mathrm{cm}^{2}$ intensity and $1 \mathrm{mHz}$ frequency, while the patient was lying in the prone position. Home-based exercises were practically taught by the physiotherapist once to all participants. The exercises consisted of isotonic and isometric strengthening exercises for trunk muscles, stretching exercises for hamstring, and lumbar extensor and hip flexor muscles. A written exercise program was given to each patient. The exercises were practiced regularly at least 15 times a day. The exercises of patients, who were eligible to move to the next stage were revised weekly. Feedback was obtained from patients about whether they did the exercises or not. Compliance with exercise was assessed via the exercise diary kept by the patient. ${ }^{[18]}$

In this study, TNE was performed by a physiotherapist, who was certified for the TNE concept, as described by Moseley and Butler. ${ }^{[19]}$ Education sessions were given to patients in a welllit and quiet room. Visuals of Why You Hurt: Therapeutic Neuroscience Education System were used during the education sessions. One-to-one speech sessions focusing on pain neurophysiology were organized twice a week for the EG. Each session lasted $40 \mathrm{~min}$. The TNE program included nociception, ion channel neurophysiology, central and peripheral sensitization, methods to help reduce sensitization, neuroplasticity, and psychosocial factors involved in the transition from acute pain to chronic pain and behavioral, cognitive responses to pain. Pictures, metaphors, stories and hand drawings were used in TNE sessions. In addition to the one-to-one speaking sessions, a brochure was prepared to explain the neurophysiology of pain in individuals with CLBP. All participants were asked to read the brochure at home and answer the questions of the physiotherapist regarding the content. Thus, the sections that were not understood 
in the previous session were re-consolidated. Education sessions were detailed with different examples and metaphors when patients had difficulty understanding concepts or ideas.

\section{Outcome measures}

The primary and secondary outcomes were evaluated at baseline and at the end of the study (Week 3). Demographic characteristics of all participants such as age, height, weight, and body mass index (BMI) were recorded at the beginning of the study.

The primary outcome measures used in the study were the VAS, which assessed pain severity and the Tampa Scale for Kinesiophobia (TSK), which evaluated kinesiophobia. The VAS is a self-reported outcome measure and provides a score for the level of pain intensity, ranging from no pain $(0$ $\mathrm{mm})$ to unbearable pain $(100 \mathrm{~mm}){ }^{[20]}$ The TSK is a questionnaire evaluating kinesiophobia due to low back pain. ${ }^{[21]}$ It is a valid and reliable questionnaire in Turkish. ${ }^{[22]}$

The secondary outcome measures were partial curl-up, modified Sorensen tests evaluating endurance of trunk muscles, and the Roland Morris Disability Questionnaire (RMDQ), evaluating disability. Trunk flexor endurance (TFE) was evaluated by partial curl-up test. ${ }^{[23]}$ Isometric trunk extensor endurance (TEE) was evaluated with the modified Sorensen test. $^{[24-26]}$ The RMDQ consists of 24 items related to physical functions and is a valid and reliable questionnaire in Turkish. ${ }^{[27]}$

\section{Statistical analysis}

Statistical analysis was performed using the IBM SPSS for Windows version 21.0 software (IBM Corp., Armonk, NY, USA). Descriptive data were expressed in mean \pm standard deviation (SD), median or number and frequency, where applicable. Levene and Shapiro-Wilk tests were used to evaluate the homogeneity, variances, and distribution of the variables and pre-post-treatment differences of the outcome measures. The pre-post group differences were evaluated by using the Mann-Whitney $U$ test for the TFE, TEE, by using independent samples t-test for the VAS and RMDQ variables, and by using two-way mixed analysis of variance (ANOVA) for the TSK variable. Intra-group differences were evaluated using the paired t-test for the for the TSK in the CG, and for the TSK, TFE, and RMDQ in the EG. The Wilcoxon signed-rank test was used for the non-normally distributed variables. A $p$ value of $<0.05$ was considered statistically significant.

\section{RESULTS}

All patients completed the three-week treatment program successfully. All patients attended all scheduled treatment sessions without any complaints. The rate of compliance with home-based exercise program was $95 \%$.

There was no statistically significant difference between the groups for the age, height, weight, and BMI ( $>>0.05)$ (Table 1). The groups also did not differ significantly at baseline for the median VAS $(\mathrm{p}=0.182)$, TSK $(p=0.056)$, TFE $(p=0.519)$, TEE $(p=0.572)$, or RMDQ scores $(\mathrm{p}=0.545)$.

However, the median VAS, TSK, and RMDQ scores improved in both groups after three weeks $(\mathrm{p}<0.05)$. In the EG, the median TEE and TFE scores were significantly higher at the post-treatment period compared to baseline $(\mathrm{p}<0.05)$, while there were no significant differences in the CG ( $>>0.05)$ (Table 2).

There was a significant main effect of time and a significant interaction between time and group on the TSK $\left(\mathrm{F}_{1}, 29=33.086, \mathrm{p}<0.001\right.$ and $\mathrm{F}_{1}, 29=16.956$, $\mathrm{p}<0.001$, respectively), although there was no significant between-subject effect $\left(F_{1}, 29=0.700\right.$,

\begin{tabular}{|c|c|c|c|c|c|c|c|}
\hline & aseline den & graphic & $\begin{array}{l}\text { ABLE } 1 \\
\text { iracteristic }\end{array}$ & of study po & ulation & & \\
\hline & Con & ol group & 15) & Experi & ental grou & $(n=16)$ & \\
\hline & Mean \pm SD & Median & Min-Max & Mean \pm SD & Median & Min-Max & $p$ \\
\hline Age (year) & $42.5 \pm 12.0$ & & & $42.1 \pm 10.1$ & & & $0.919 \dagger$ \\
\hline Height $(\mathrm{cm})$ & $162.1 \pm 8.1$ & & & $165.1 \pm 6.4$ & & & $0.252 \dagger$ \\
\hline Weight (kg) & $69.6 \pm 12.2$ & & & $74.6 \pm 14.4$ & & & $0.304 \dagger$ \\
\hline Body mass index $\left(\mathrm{kg} / \mathrm{m}^{2}\right)$ & & 26.2 & $20.6-31.3$ & & 26.4 & $21.3-38.7$ & $0.843 \ddagger$ \\
\hline
\end{tabular}




\begin{tabular}{|c|c|c|c|c|c|c|c|c|}
\hline \multicolumn{9}{|c|}{$\begin{array}{l}\text { TABLE } 2 \\
\text { me measures within and between groups }\end{array}$} \\
\hline & \multicolumn{4}{|c|}{ Control group $(n=15)$} & \multicolumn{4}{|c|}{ Experimental group $(n=16)$} \\
\hline & Mean \pm SD & Median & Min-Max & $p^{*}$ & Mean \pm SD & Median & Min-Max & $p^{*}$ \\
\hline \multicolumn{9}{|l|}{ VAS (mm) } \\
\hline Baseline & & 70 & $23-100$ & \multirow{3}{*}{$0.003^{* *}$} & & 51.5 & $12-100$ & \multirow{2}{*}{$<0.001^{* *}$} \\
\hline Post-treatment & & 25 & $12-100$ & & & 8.5 & $0-53$ & \\
\hline Change & $33.8 \pm 29.5$ & -31 & $-83-26$ & & $-35.9 \pm 28.3$ & -26 & $-93--3$ & $0.845 \S$ \\
\hline \multicolumn{9}{|l|}{ TSK (point) } \\
\hline Baseline & $43.7 \pm 7.0$ & 44 & $29-56$ & \multirow{3}{*}{$0.002 \ddagger$} & $49.4 \pm 8.6$ & 47.5 & $36-64$ & \multirow{2}{*}{$<0.001 \ddagger$} \\
\hline Post-treatment & $40.9 \pm 7.0$ & 42 & $29-51$ & & $32.1 \pm 5.7$ & 32 & $24-43$ & \\
\hline Change & $-2.9 \pm 6.4$ & -5 & $-12-14$ & & $-17.3 \pm 12.1$ & -15 & $-37-6$ & $<0.0019$ \\
\hline \multicolumn{9}{|l|}{ TFE (repetition) } \\
\hline Baseline & & 18 & $2-35$ & \multirow{3}{*}{$0.614^{\star *}$} & $19.7 \pm 8.5$ & 19.5 & $0-31$ & \multirow{2}{*}{$0.001 \ddagger$} \\
\hline Post-treatment & & 18 & $4-44$ & & $27.3 \pm 7.4$ & 25 & $18-40$ & \\
\hline Change & & -1 & $-15-34$ & & & 6.5 & $-7-20$ & $0.006 \dagger$ \\
\hline \multicolumn{9}{|l|}{ TEE (s) } \\
\hline Baseline & & 60 & $20-120$ & \multirow{3}{*}{$0.064^{* *}$} & & 39 & $7-300$ & \multirow{2}{*}{$0.010^{* *}$} \\
\hline Post-treatment & & 70 & $15-300$ & & & 66.5 & $20-310$ & \\
\hline Change & & 9 & $-35-210$ & & & 31.5 & $-36-155$ & $0.342 \dagger$ \\
\hline \multicolumn{9}{|l|}{ RMDQ (point) } \\
\hline Baseline & & 19 & $6-24$ & \multirow{2}{*}{$0.002^{\star *}$} & $15.1 \pm 6.3$ & 16.5 & $0-24$ & \multirow{2}{*}{$<0.001 \ddagger$} \\
\hline Post-treatment & & 8 & $0-23$ & & $6.3 \pm 4.9$ & 6 & $0-17$ & \\
\hline Change & $-5.7 \pm 4.4$ & -7 & $-14-2$ & & $-8.8 \pm 5.5$ & -8.5 & $-18-0$ & $0.098 \S$ \\
\hline
\end{tabular}

$\mathrm{p}=0.410$ ). The groups differed significantly for the absolute value of the difference for TFE in favor of the EG $(\mathrm{p}<0.05)$, while there were no statistically significant difference for the absolute value of the differences of the VAS, TEE, and RMDQ scores $(\mathrm{p}>0.05)$ (Table 2).

\section{DISCUSSION}

This randomized-controlled study showed that TNE combined with a physiotherapy program consisting of exercise and electrophysical modalities in CLBP patients was superior to a physiotherapy program alone. As a result, kinesiophobia and TFE improved further, when TNE was combined with physiotherapy program in CLBP patients.

Although some authors have suggested that additional TNE sessions to the physiotherapy program may cause pain differences in the group, ${ }^{[28-30]}$ some others have advocated that additional TNE sessions resulted no significant group differences. ${ }^{[31,32,33]}$ Additionally, Ryan et al. ${ }^{[33]}$ claimed that the combination of exercise and TNE revealed no additional benefit in terms of pain due to the use of a language based on structural and pathological terminology. Pain decreased in the both of the groups in our study, although there was no significant difference between the groups. In order to interpret the effect of TNE sessions on the pain more effectively, the level of pain centralization of participants would be determined in further studies.

Kinesiophobia significantly improved with the TNE and physiotherapy applications in the systematic review including patients with CLBP ${ }^{[17]}$ The objective of neuroscience education is decreasing of the fear of movement or reinjury. We also attempted to integrate TNE concept with an exercise program to provide an additional benefit to kinesiophobia. Of note, the assumption of that movement is not so dangerous is the main rationale of our trial. Our results related to kinesiophobia are in consistency with the literature. 
In this study, the improvement of TFE was higher in the EG than the CG, while there was no significant difference in the TEE. In the literature, there is no study evaluating the endurance of trunk muscles among the researches evaluating the efficacy of physiotherapy combined with TNE in patients with CLBP. However, a study examined the effect of TNE in individuals with chronic neck pain and evaluating neck flexor endurance. ${ }^{[34]}$ In this study, neck flexor endurance was increased in the groups which TNE was applied. The authors attributed the results to the decrease in kinesiophobia and, thus, to the increase in physical activity with TNE sessions. In addition, back endurance time was found to be shorter in CLBP patients, compared to healthy individuals in another study. ${ }^{[26]}$ Biering-Sørensen ${ }^{[35]}$ also reported that a position-holding time less than $176 \mathrm{sec}$ could predict low back pain in males. Many factors such as BMI, age, and sex were reported to affect TEE and TFE. ${ }^{[36,37]}$ However, there is no study on flexor and extensor muscle response in the emergence of exercise and physical therapy effects in patients with low back pain. In this study, the median TEE time was shorter than $176 \mathrm{sec}$ in all of the CG and $81 \%$ of the EG. Although there was no significant difference between the groups in terms of BMI, age, and sex at baseline, pre-obesity was recorded in $50 \%$ of the EG and in $40 \%$ of the CG. Additionally, $69 \%$ of the patients were over 40 years old, and $88 \%$ were women in the EG, while $67 \%$ of the patients were over 40 years old and $89 \%$ were women in the CG. This finding indicates that anthropometric properties, age, and sex should be taken into consideration in the assessment of the effect of physical therapy and exercise on trunk flexor and TEE and strength. It has also been shown in the literature that brain activity changes after TNE sessions. In a relevant case study, diffuse brain activity displayed during voluntary activity of the transverse abdominus muscle decreased after TNE. ${ }^{[38]}$ This result shows that pain physiology education changes brain activity during physical performance. In the light of these data, pain physiology education can be speculated to be effective in overcoming the obstacles in improving motor control of trunk muscles in patients with low back pain. Since our study only evaluated TFE with partial curl-up test, further studies are needed to determine the clinical benefit of our results regarding the TFE.

There are many studies investigating the effect of TNE on disability and using RMDQ to assess disability for patients with CLBP in the literature. ${ }^{[28,29,32,39]}$ Only one of the studies using
RMDQ as an evaluation method, however, investigated the efficacy of TNE, when added to physical therapy applications. ${ }^{[32]}$ Similar to our study, the improvement in the disability scores of the groups was not significantly different from each other in this study. Improvement of disability may stem from the stronger belief of the effectiveness of physical therapy among Turkish population. In another study, physical therapy program consisting of electrophysical agents and home-based exercise program significantly decreased disability. ${ }^{[40]}$ In our study, factors which could positively affect the outcome measures such as patients' beliefs related to treatment effects and interaction between the patient and physiotherapist were not evaluated. Further studies investigating these parameters would provide a more accurate information on this topic.

The lack of a long follow-up period is the main limitation of this study. Future trials may also benefit of greater sample size and longer follow-up period to increase the generalizability of the results. Another limitation of this study is that we were unable to control whether patients' knowledge of pain neurophysiology increased after education. Since the Turkish validity and reliability studies of the Neurophysiology of Pain Questionnaire have not been conducted yet, the increase in the pain neurophysiology knowledge level of the participants could not be determined. In further studies, the cultural adaptation of the Neurophysiology of Pain Questionnaire ${ }^{[41]}$ into Turkish is planned.

The strength of this study is implementing of both education and physiotherapy in the same session and by a single physiotherapist. In previous studies, exercise methods which were not based on the neuroscience education concept reinforced patients' beliefs about tissue damage. ${ }^{[33]}$ Our study allows to be aware that perceived pain after exercise does not arise from tissue damage. This awareness motivated patients to make exercise. Also, our study is the first study to investigate TNE combined with physiotherapy program consisting of electrophysical modalities and home-based exercise program in the Turkish population.

In conclusion, combined therapy which consists of physiotherapy with TNE is more effective than physiotherapy alone on kinesiophobia and the TFE and, in a short period of time, in patients with CLBP. However, there is still a need for large-scale, long-term, randomized-controlled trials investigating the effect of additional methods to reinforce the integration of TNE 
and physiotherapy methods on the outcome measures in CLBP patients.

\section{Acknowledgements}

We thank all participants for their participation in this study.

\section{Declaration of conflicting interests}

The authors declared no conflicts of interest with respect to the authorship and/or publication of this article.

\section{Funding}

This study was supported by the Scientific Research Projects Coordination Unit (Project number: 2016SABE009).

\section{REFERENCES}

1. Classification of chronic pain. Descriptions of chronic pain syndromes and definitions of pain terms. Prepared by the International Association for the Study of Pain, Subcommittee on Taxonomy. Pain Suppl 1986;3:S1-226.

2. Pincus T, Burton AK, Vogel S, Field AP. A systematic review of psychological factors as predictors of chronicity/ disability in prospective cohorts of low back pain. Spine (Phila Pa 1976) 2002;27:E109-20.

3. Larivière $C$, Bilodeau $M$, Forget $R$, Vadeboncoeur R, Mecheri H. Poor back muscle endurance is related to pain catastrophizing in patients with chronic low back pain. Spine (Phila Pa 1976) 2010;35:E1178-86.

4. Stochkendahl MJ, Kjaer P, Hartvigsen J, Kongsted A, Aaboe J, Andersen M, et al. National Clinical Guidelines for nonsurgical treatment of patients with recent onset low back pain or lumbar radiculopathy. Eur Spine J 2018;27:60-75.

5. Qaseem A, Wilt TJ, McLean RM, Forciea MA; Clinical guidelines committee of the american college of physicians. noninvasive treatments for acute, subacute, and chronic low back pain: A Clinical Practice Guideline From the American College of Physicians. Ann Intern Med 2017;166:514-30.

6. Steiger F, Wirth B, de Bruin ED, Mannion AF. Is a positive clinical outcome after exercise therapy for chronic nonspecific low back pain contingent upon a corresponding improvement in the targeted aspect(s) of performance? A systematic review. Eur Spine J 2012;21:575-98.

7. Moseley GL, Gallace A, Spence C. Bodily illusions in health and disease: physiological and clinical perspectives and the concept of a cortical 'body matrix'. Neurosci Biobehav Rev 2012;36:34-46.

8. Wallwork SB, Butler DS, Wilson DJ, Moseley GL. Are people who do yoga any better at a motor imagery task than those who do not? Br J Sports Med 2015;49:123-7.

9. Wand BM, Parkitny L, O'Connell NE, Luomajoki H, McAuley JH, Thacker M, et al. Cortical changes in chronic low back pain: current state of the art and implications for clinical practice. Man Ther 2011;16:15-20.

10. Brox JI, Storheim K, Grotle M, Tveito TH, Indahl A, Eriksen HR. Systematic review of back schools, brief education, and fear-avoidance training for chronic low back pain. Spine J 2008;8:948-58.
11. Engers $A$, Jellema $P$, Wensing $M$, van der Windt DA, Grol R, van Tulder MW. Individual patient education for low back pain. Cochrane Database Syst Rev 2008;2008:CD004057.

12. Heymans MW, van Tulder MW, Esmail R, Bombardier C, Koes BW. Back schools for nonspecific low back pain: a systematic review within the framework of the Cochrane Collaboration Back Review Group. Spine (Phila Pa 1976) 2005;30:2153-63.

13. Liddle SD, Gracey JH, Baxter GD. Advice for the management of low back pain: a systematic review of randomised controlled trials. Man Ther 2007;12:310-27.

14. Moseley GL. Reconceptualising pain according to modern pain science. Physical Therapy Reviews 2007;12:169-78.

15. Leeuw M, Goossens ME, Linton SJ, Crombez G, Boersma K, Vlaeyen JW. The fear-avoidance model of musculoskeletal pain: current state of scientific evidence. J Behav Med 2007;30:77-94.

16. Fletcher C, Bradnam L, Barr C. The relationship between knowledge of pain neurophysiology and fear avoidance in people with chronic pain: A point in time, observational study. Physiother Theory Pract 2016;32:271-6.

17. Wood L, Hendrick PA. A systematic review and metaanalysis of pain neuroscience education for chronic low back pain: Short-and long-term outcomes of pain and disability. Eur J Pain 2019;23:234-49.

18. Ay S, Evcik D, Gökçe-Kutsal Y, Toraman F, Okumuş M, Eyigör $S$, et al. Compliance to home-based exercise therapy in elderly patients with knee osteoarthritis. Turk J Phys Med Rehab 2016;62:323-8.

19. Moseley GL, Butler DS. Fifteen years of explaining pain: The past, present, and future. J Pain 2015;16:807-13.

20. Carlsson AM. Assessment of chronic pain. I. Aspects of the reliability and validity of the visual analogue scale. Pain 1983;16:87-101.

21. Miller RP, Kori S and Todd D. The tampa scale: a measure of kinesiophobia. Clin J Pain 1991;7:51-2.

22. Tunca Yllmaz Ö, Yakut Y, Uygur F, Uluğ N. Tampa Kinezyofobi Ölçeği'nin Türkçe versiyonu ve test-tekrar test güvenirliği. Fizyoter Rehabil 2011;22:44-9.

23. Marshall PW, Murphy BA. Evaluation of functional and neuromuscular changes after exercise rehabilitation for low back pain using a Swiss ball: a pilot study. J Manipulative Physiol Ther 2006;29:550-60.

24. Ito T, Shirado O, Suzuki H, Takahashi M, Kaneda K, Strax TE. Lumbar trunk muscle endurance testing: an inexpensive alternative to a machine for evaluation. Arch Phys Med Rehabil 1996;77:75-9.

25. Demoulin C, Vanderthommen M, Duysens C, Crielaard JM. Spinal muscle evaluation using the Sorensen test: a critical appraisal of the literature. Joint Bone Spine 2006;73:43-50.

26. Süüden E, Ereline J, Gapeyeva H, Pääsuke M. Low back muscle fatigue during Sørensen endurance test in patients with chronic low back pain: relationship between electromyographic spectral compression and anthropometric characteristics. Electromyogr Clin Neurophysiol 2008;48:185-92. 
27. Küçükdeveci AA, Tennant A, Elhan AH, Niyazoglu H. Validation of the Turkish version of the Roland-Morris Disability Questionnaire for use in low back pain. Spine (Phila Pa 1976) 2001;26:2738-43.

28. Wälti P, Kool J, Luomajoki H. Short-term effect on pain and function of neurophysiological education and sensorimotor retraining compared to usual physiotherapy in patients with chronic or recurrent non-specific low back pain, a pilot randomized controlled trial. BMC Musculoskelet Disord $2015 ; 16: 83$.

29. Moseley L. Combined physiotherapy and education is efficacious for chronic low back pain. Aust J Physiother 2002;48:297-302.

30. Pires D, Cruz EB, Caeiro C. Aquatic exercise and pain neurophysiology education versus aquatic exercise alone for patients with chronic low back pain: a randomized controlled trial. Clin Rehabil 2015;29:538-47.

31. Louw A, Farrell K, Landers M, Barclay M, Goodman E, Gillund J, et al. The effect of manual therapy and neuroplasticity education on chronic low back pain: a randomized clinical trial. J Man Manip Ther 2017;25:227-34.

32. Téllez-García M, de-la-Llave-Rincón AI, Salom-Moreno J, Palacios-Ceña M, Ortega-Santiago R, Fernández-de-LasPeñas C. Neuroscience education in addition to trigger point dry needling for the management of patients with mechanical chronic low back pain: A preliminary clinical trial. J Bodyw Mov Ther 2015;19:464-72.

33. Ryan CG, Gray HG, Newton M, Granat MH. Pain biology education and exercise classes compared to pain biology education alone for individuals with chronic low back pain: a pilot randomised controlled trial. Man Ther 2010;15:382-7.

34. Beltran-Alacreu H, López-de-Uralde-Villanueva I, Fernández-Carnero J, La Touche R. Manual Therapy, Therapeutic Patient Education, and Therapeutic Exercise, an Effective Multimodal Treatment of Nonspecific Chronic Neck Pain: A Randomized Controlled Trial. Am J Phys Med Rehabil 2015;94(10 Suppl 1):887-97.

35. Biering-Sørensen F. Physical measurements as risk indicators for low-back trouble over a one-year period. Spine (Phila Pa 1976) 1984;9:106-19.

36. Shah NB, Kadu S, Anap DB, Mamania JA. Overweight, a culprit affecting back endurance: A cross sectional study. IJCBR 2017;3:18-21.

37. Hasan NAKAK, Kamal HM, Hussein ZA. Relation between body mass index percentile and muscle strength and endurance. Egypt J Med Hum Genet 2016;17:367-72.

38. Moseley GL. Widespread brain activity during an abdominal task markedly reduced after pain physiology education: fMRI evaluation of a single patient with chronic low back pain. Aust J Physiother 2005;51:49-52.

39. Moseley GL, Nicholas MK, Hodges PW. A randomized controlled trial of intensive neurophysiology education in chronic low back pain. Clin J Pain 2004;20:324-30.

40. Koldaş Doğan S, Sonel Tur B, Kurtaiş Y, Atay MB. Comparison of three different approaches in the treatment of chronic low back pain. Clin Rheumatol 2008;27:873-81.

41. Catley MJ, O'Connell NE, Moseley GL. How good is the neurophysiology of pain questionnaire? A Rasch analysis of psychometric properties. J Pain 2013;14:818-27. 